\title{
Ventricular restraint therapy for heart failure: The right ventricle is different from the left ventricle
}

\author{
Lawrence S. Lee, MD, ${ }^{a}$ Ravi K. Ghanta, MD, ${ }^{a}$ Suyog A. Mokashi, MD, ${ }^{a}$ Otavio Coelho-Filho, MD, ${ }^{b}$ \\ Raymond Y. Kwong, MD, MPH, ${ }^{\mathrm{b}}$ R. Morton Bolman III, MD, ${ }^{\mathrm{a}}$ and Frederick Y. Chen, MD, PhD ${ }^{\mathrm{a}}$
}

\begin{abstract}
Objective: Effects of ventricular restraint on the left ventricle are well documented, but effects on the right ventricle are not. We hypothesized that restraint affects the right and left ventricles differently.

Methods: We studied acute effects of restraint on left and right ventricular mechanics in healthy sheep $(n=14)$ with our previously described technique of adjustable and measurable restraint. Transmural pressure, myocardial oxygen consumption indices, diastolic compliance, and end-systolic elastance were assessed at 4 restraint levels for both ventricles. We then studied long-term effects of restraint for 4 months in an ovine model of ischemic dilated cardiomyopathy $(\mathrm{n}=6)$. Heart failure was induced by coronary artery ligation, and polypropylene mesh was wrapped around the heart to simulate clinical restraint therapy. All subjects were followed up with serial cardiac magnetic resonance imaging to assess left and right ventricular volumes and function.
\end{abstract}

Results: Restraint decreased left ventricular transmural pressure $(P<.03)$ and myocardial oxygen consumption indices $(P<.05)$ but not left ventricular diastolic compliance $(P=.52)$. Restraint had no effect on right ventricular transmural pressure $(P=.82)$ or myocardial oxygen consumption indices $(P=.72)$ but reduced right ventricular diastolic compliance $(P<.01)$. In long-term studies, restraint led to reverse left ventricular remodeling with decreased left ventricular end-diastolic volume $(P<.006)$ but did not affect right ventricular end-diastolic volume $(P=.82)$.

Conclusions: Ventricular restraint affects the left and right ventricles differently. Benefits of restraint for right ventricular function are unclear. The left ventricle can tolerate more restraint than the right ventricle. With current devices, the right ventricle may limit overall therapeutic efficacy. (J Thorac Cardiovasc Surg 2010;139:1012-8)

Ventricular restraint is a nontransplant surgical treatment for heart failure in which the entire epicardial surface is wrapped with a prosthetic material. ${ }^{1,2}$ The intent is to provide circumferential diastolic support to the failing heart and prevent progressive ventricular remodeling. Although no clinically approved restraint device is currently available for use, numerous animal studies and clinical trials have demonstrated that devices such as the Acorn CorCap Cardiac Support Device (Acorn Cardiovascular, Inc, St Paul, Minn) can induce reverse remodeling of the left ventricle (LV) and lead to improvement in LV volumes, ejection fraction (EF), and sphe-

From the Divisions of Cardiac Surgery a and Cardiology, ${ }^{\mathrm{b}}$ Brigham and Women's Hospital, Harvard Medical School, Boston, Mass.

Disclosures: Supported by Brigham and Women's Hospital, Department of Surgery (F.Y.C.), Brigham and Women's Hospital, Cardiac Surgery Research Fund (R.M.B.), Harvard Medical School, Warren Whitman Fellowship (L.S.L.), and the National Institutes of Health grants T32HL076130 (L.S.L.), RO1HL090862 (F.Y.C.), and R01HL091157 (R.Y.K.). Ethicon, Inc, Somerville, NJ, provided the polypropylene mesh used in this study.

Read at the Thirty-fifth Annual Meeting of The Western Thoracic Surgical Association, Banff, Alberta, Canada, June 24-27, 2009.

Received for publication June 19, 2009; revisions received Aug 13, 2009; accepted for publication Sept 2, 2009.

Address for reprints: Frederick Y. Chen, MD, PhD, Division of Cardiac Surgery, Brigham and Women's Hospital, 75 Francis St, Boston, MA 02115 (E-mail: fchen@ partners.org).

$0022-5223 / \$ 36.00$

Copyright (c) 2010 by The American Association for Thoracic Surgery

doi: $10.1016 /$ j.jtcvs.2009.09.064 ricity index. ${ }^{3-14}$ The precise mechanics through which restraint engenders these changes, however, remains unknown. With our previously described technique in which the amount of applied restraint can be measured and quantified (Figure 1), we demonstrated that ventricular restraint decreases LV transmural myocardial pressure $\left(\mathrm{P}_{\mathrm{tm}}\right)$ and indices of myocardial oxygen consumption $\left(\mathrm{MvO}_{2}\right)$ in a large animal model. ${ }^{15-16}$ These results imply that decreased LV wall stress is one mechanism through which restraint promotes reverse remodeling. We also showed that restraint level determines the degree of improvement in $\mathrm{P}_{\mathrm{tm}}$ and indices of $\mathrm{MvO}_{2}$, implying that the amount of restraint applied is critical in determining therapeutic efficacy.

Most published studies analyzing the effects of ventricular restraint have focused on the LV, because LV dysfunction is the primary pathology for which restraint therapy is indicated. Thus restraint has logically targeted improvement in LV function. All current ventricular restraint devices, however, involve the application of epicardial pressure around the entire heart, including the right ventricle (RV). Because the RV is restrained, alterations in right heart mechanics and physiology are possible. To date, however, there have been no definitive studies evaluating the effect of ventricular restraint on the RV.

In this study, we hypothesized that ventricular restraint has different effects on RV function and mechanics than on those of the LV. We tested this hypothesis by performing 

Abbreviations and Acronyms
AMVR $=$ adjustable and measurable
$\mathrm{C}_{\mathrm{d}}=$ diastolic compliance
$\mathrm{CVP}=$ central venous pressure
$\mathrm{EDP}=$ end-diastolic pressure
$\mathrm{EDV}=$ end-diastolic volume
$\mathrm{E}_{\mathrm{es}} \quad=$ end-systolic elastance
$\mathrm{EF}=$ ejection fraction
$\mathrm{LV}=$ left ventricle
MAP $=$ mean arterial pressure
$\mathrm{MvO}_{2}=$ myocardial oxygen consumption
$\mathrm{P}_{\max }=$ maximal pressure tested
$\mathrm{P}_{\mathrm{tm}}=$ transmural myocardial pressure
$\mathrm{RV} \quad=$ right ventricle

both acute and long-term studies of ventricular restraint in a sheep model.

\section{MATERIALS AND METHODS \\ Study Overview}

This study was performed in 2 parts. (1) Acute, terminal studies evaluated the effect of ventricular restraint level on $\mathrm{RV}$ and $\mathrm{LV} \mathrm{P}_{\mathrm{tm}}$, indices of $\mathrm{MvO}_{2}$, compliance, and hemodynamics. (2) Long-term, 4-month longitudinal studies investigated the effects of simulated clinical restraint on RV and $\mathrm{LV}$ remodeling in an ovine model of ischemic dilated cardiomyopathy.

A total of 20 (14 for acute studies, 6 for long-term studies) adult male sheep (weight range 30-40 kg) were used in this study. All animals received humane care in compliance with the Guide for Care and Use of Laboratory Animals (www.nap.edu/catalog/5140.html). The protocol was approved by the Institutional Animal Care and Use Committee at Harvard Medical School.

\section{Acute Studies: Effects of Restraint Level on Ventricular Mechanics}

Adjustable and measurable ventricular restraint. Because current clinical restraint devices such as the Acorn CorCap Cardiac Support Device do not allow either the measurement or adjustment of wrap tightness, restraint is applied at an arbitrary level of tightness. ${ }^{6,9,23}$ To address these limitations, we have previously developed and described adjustable and measurable ventricular restraint (AMVR), in which a fluidfilled epicardial balloon is placed around the entire ventricular surface. ${ }^{16}$ The balloon is surgically placed around the heart and secured to the atrioventricular groove.

The AMVR balloon is hemiellipsoidal in shape and composed of medical grade polyurethane sheets (Polyzen, Inc, Apex, NC). Each balloon is composed of two 1-mm thick layers. The outer layer of the balloon is flexible but nonstretchable, whereas the inner layer is redundant. An access line placed between the layers allows measurement of the pressure within the balloon lumen, as well as the addition or withdrawal of fluid. Because the outer layer of the balloon is nonstretchable, fluid introduced into the balloon lumen has only one direction of filling space-inward, toward the heart. This creates a tighter wrap. Conversely, withdrawal of fluid from the balloon lumen creates a looser wrap. The balloon access line is connected to a Statham P10EZ pressure transducer (SpectraMed, Oxford, Calif). By measuring the luminal pressure within the balloon when the heart is largest-end dias- tole-wrap tightness (or restraint level) may be precisely quantified. To change restraint level, fluid is added or removed from the balloon while balloon luminal pressure is monitored in real time. At end diastole, the fluid within the balloon lumen and access line is static. Cardiac magnetic resonance imaging has confirmed this (unpublished data). Because the fluid is static, the pressure measured by the access line should reflect the entire balloon luminal pressure.

Pressure-volume analysis. Fourteen normal sheep were placed under general anesthesia and underwent AMVR balloon placement by median sternotomy. A 16-gauge intravenous line was placed in the left external jugular vein for access and measurement of central venous pressure (CVP). An electromagnetic aortic flow probe (Carolina Medical Electronics, King, NC) was placed to measure aortic flow. High-fidelity micromanometers (Millar Instruments, Houston, Texas) were placed in the LV, RV, and aorta. An $8 \mathrm{~F}$ conductance catheter for volume measurement (Webster Laboratories, Baldwin Park, Calif) was placed in the RV or LV. ${ }^{17-19}$ All electrocardiographic and hemodynamic signals were sampled at $200 \mathrm{~Hz}$. We arbitrarily defined the maximal pressure tested $\left(\mathrm{P}_{\max }\right)$ in our study as the level at which mean arterial pressure (MAP) fell by $10 \mathrm{~mm} \mathrm{Hg}$, indicative of tamponade physiology. In our animal model, $\mathrm{P}_{\max }$ was $8.0 \mathrm{~mm} \mathrm{Hg}$. For each subject, all signals were recorded at 4 sequential restraint levels: 0 (baseline), $3.0 \mathrm{~mm} \mathrm{Hg}\left(\mathrm{P}_{\max } / 3\right), 5.0 \mathrm{~mm} \mathrm{Hg}\left(2 \mathrm{P}_{\max } / 3\right)$, and $8.0 \mathrm{~mm} \mathrm{Hg}$ $\left(\mathrm{P}_{\max }\right)$. All data were collected for 20 beats and with the ventilator off to avoid respiratory variations. The heart rate varied among animals (range $55-115$ beats/min) but remained fairly consistent for any given subject at all restraint levels tested. At each restraint level, an inferior vena caval occlusion was performed to determine the RV and LV end-systolic elastance $\left(\mathrm{E}_{\mathrm{es}}\right)$ and diastolic compliance $\left(\mathrm{C}_{\mathrm{d}}\right)$ values.

Data were analyzed on a microcomputer with the program MATLAB (The Mathworks, Natick, Mass). End diastole was defined as the time point in the cardiac cycle that corresponded to the $\mathrm{R}$ wave on the electrocardiogram, which closely represents closure of the mitral valve. Begin ejection was defined as the point at which aortic flow first became nonzero, whereas end systole was defined as the point at which aortic flow became zero after the beginning of ejection. Hemodynamic signals were ensemble averaged across 10 beats. $P_{t m}$ across the heart wall was defined as the ventricular pressure minus the epicardial pressure (as measured by the balloon). The transmural tension-time index was calculated by integrating $\mathrm{P}_{\mathrm{tm}}$ with respect to time across the cardiac cycle. The end-systolic pressure-volume relationship and the end-diastolic pressure-volume relationship were determined from the caval occlusion data by the procedure of Kono and colleagues. ${ }^{20}$ The transmural pressure-volume area was calculated for each restraint level. ${ }^{20-21}$

\section{Long-Term Studies: Effects of Restraint on Ventricular Morphology and Function}

Heart failure model. A postinfarction ovine model of heart failure, previously described by Moainie and associates, ${ }^{22}$ was utilized. This model includes many of the features of human ischemic dilated cardiomyopathy and LV remodeling, such as increased LV end-diastolic volume (EDV) and end-systolic volume, increased sphericity index, reduced LV EF, and decreased systolic wall thickening. A left anterior thoracotomy was performed through the 4th intercostal space in 6 sheep. The first 2 diagonal branches of the left anterior descending coronary artery were identified and ligated with 4-0 polypropylene sutures. The thoracotomy was closed in layers, and the animal was allowed to recover. Cardiac magnetic resonance imaging was performed 8 weeks after infarction to document heart failure. By this time, heart failure developed in all animals, with LV EF less than $40 \%$ and a $100 \%$ increase in LV EDV from baseline. There was hypokinesis of the anterior to anterolateral wall, consistent with infarction of the area supplied by the ligated coronary arteries.

Simulated clinical ventricular restraint. To simulate clinical restraint therapy, a polypropylene mesh (Ethicon, Inc, Somerville, NJ) was 


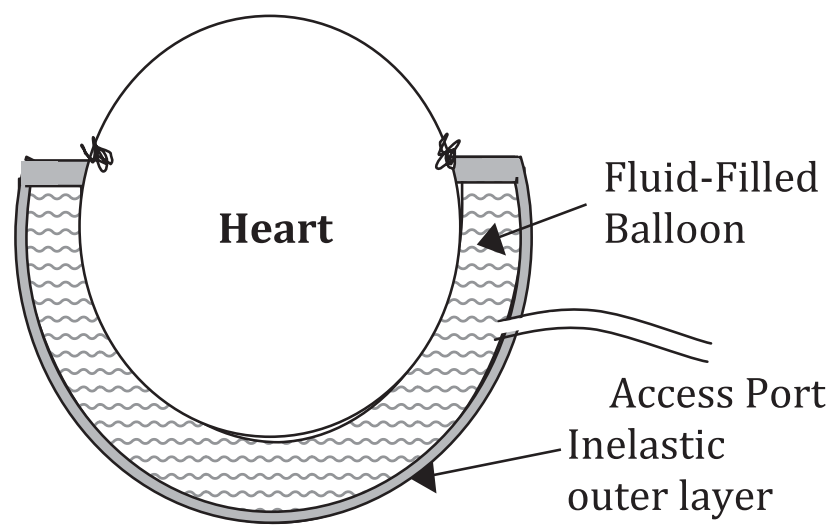

FIGURE 1. Adjustable and measurable balloon ventricular restraint (AMVR) device: a half-ellipsoidal fluid-filled balloon. Restraint level may be quantified by measuring luminal pressure at end diastole. Restraint level may be adjusted by changing the volume of fluid instilled in balloon. The device is placed around both ventricles and secured to heart along the atrioventricular groove.

implanted in all 6 sheep with heart failure. After induction of general anesthesia, a median sternotomy was performed, and the mesh was placed around the heart in accordance with guidelines used for placement of the Acorn CorCap restraint device in clinical trials. The mesh was wrapped around the heart and secured to the atrioventricular groove such that LV EDV was decreased by $5 \%$ to $10 \%$ according to intraoperative epicardial echocardiography. ${ }^{23,26}$ The incision was closed in layers, and the animal was allowed to recover.
Cardiac magnetic resonance imaging. Serial cardiac magnetic resonance imaging was performed in all animals at 8 weeks after coronary ligation but before restraint wrap implantation to confirm development of heart failure, and then bimonthly after wrap implantation (Figure 2). Imaging was performed with a 3-T magnetic resonance scanner (Signa CV/i; General Electric Healthcare, Milwaukee, Wis). All acquisitions were obtained with an 8-element cardiac phased-array surface coil with the animal in lateral decubitus position under general anesthesia and with proper ventilation. Peripheral pulse gating and breath holding were used as much as possible to minimize cardiac and respiratory motions, respectively. After cardiac localization, cine imaging of cardiac function was performed with cine steady-state free-precession fast-gradient echocardiography in 8 to 12 parallel short-axis slices (8-mm thickness, 0 - $\mathrm{mm}$ skip) covering the entire $\mathrm{LV}$ and 3 radial long-axis planes. Typical cine imaging parameters included repetition time of $3.4 \mathrm{~ms}$, echo time of $1.2 \mathrm{~ms}$, flip angle of $45^{\circ}$, number of excitations of 2, in-plane spatial resolution of $1.5 \times 1.5 \mathrm{~mm}$, and views per segment of 12 , providing a temporal resolution of approximately $40 \mathrm{~ms}^{24}$

Cine function analysis was performed off-line with validated software (QMASS 7.1; Medis Medical Imaging Systems, Inc, Leiden, The Netherlands) ${ }^{25}$ The cardiac phase that demonstrated the largest LV cavity size was defined as end diastole, and that with the smallest LV cavity size as end systole. A single experienced observer manually traced the endocardial contours of the RV and the LV to determine the ventricular chamber volumes at end diastole and end systole. The papillary muscles were included in the ventricular cavity volume (Figure $2, C$ ). If the basal slice contained both ventricular and atrial myocardium, the contours were drawn up to the junction of the atrium and the ventricle and joined by a straight line through the blood pool. For the RV basal slice in both end diastole and end systole, if the pulmonary valve was visible, only the portion of the volume surrounded by trabeculated myocardium below the level of the pulmonary valve was considered ventricle and included. For the inflow portion of the RV, the blood volume was excluded from the RV volume if the
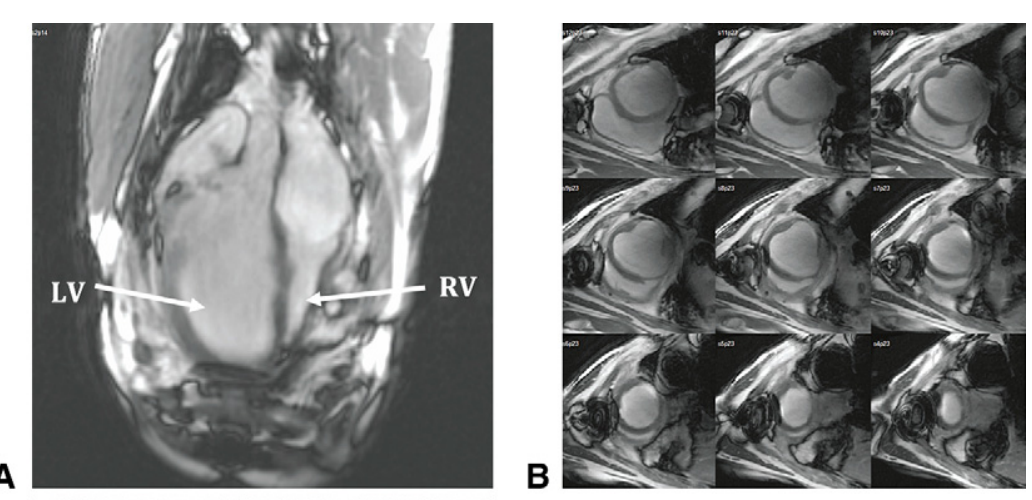

A

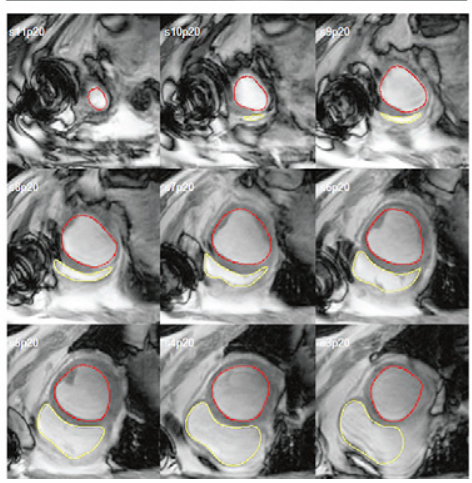

B

C

FIGURE 2. Cardiac magnetic resonance imaging of ovine model of heart failure. A, Four-chamber long-axis view showing position of heart within thoracic cavity. B, Short-axis views of heart. C, Short-axis views with left ventricular $(L V$, red $)$ and right ventricular $(R V$, yellow) endocardial borders delineated at end diastole. 
TABLE 1. Effects of restraint level on hemodynamics, ventricular mechanics, and myocardial energetics

\begin{tabular}{lcccc}
\hline & \multicolumn{4}{c}{ Restraint level (mm Hg) } \\
\cline { 2 - 5 } & $\mathbf{0}$ & $\mathbf{3}$ & $\mathbf{5}$ & $\mathbf{8}$ \\
\hline Mean arterial pressure (mm Hg) & 53.2 & 54.2 & $44.7^{*}$ & $40.4^{*}$ \\
Central venous pressure (mm Hg) & 12.1 & 12.9 & $14.2^{*}$ & $16.7^{*}$ \\
Left ventricle & & & & \\
$\mathrm{P}_{\mathrm{tm}}(\mathrm{mm} \mathrm{Hg})$ & 31.8 & $28.1^{*}$ & $23.5^{*}$ & $18.7^{*}$ \\
$\mathrm{EDP}(\mathrm{mm} \mathrm{Hg})$ & 7.3 & 7.8 & 7.9 & 8.5 \\
$\mathrm{E}_{\mathrm{es}}(\mathrm{mm} \mathrm{Hg} / \mathrm{mL})$ & 0.46 & 0.43 & 0.44 & 0.53 \\
$\mathrm{C}_{\mathrm{d}}(\mathrm{mL} / \mathrm{mm} \mathrm{Hg})$ & 2.94 & 2.43 & 2.09 & 3.12 \\
$\mathrm{TTI}(\mathrm{mm} \mathrm{Hg} \mathrm{s})$ & 16.8 & $14.5^{*}$ & $12.6^{*}$ & $10.0^{*}$ \\
PVA $(\mathrm{mm} \mathrm{Hg} \mathrm{mL)}$ & 2558 & $1983^{*}$ & $1461^{*}$ & $1299^{*}$ \\
Right ventricle & & & & \\
$\mathrm{P}_{\mathrm{tm}}(\mathrm{mm} \mathrm{Hg})$ & 10.8 & 10.8 & 10.9 & 10.5 \\
EDP $(\mathrm{mm} \mathrm{Hg})$ & 3.7 & $6.1^{*}$ & $7.9^{*}$ & $11.0^{*}$ \\
$\mathrm{E}_{\mathrm{es}}(\mathrm{mm} \mathrm{Hg} / \mathrm{mL})$ & 0.7 & 0.97 & 0.85 & 1.06 \\
$\mathrm{C}_{\mathrm{d}}(\mathrm{mL} / \mathrm{mm} \mathrm{Hg})$ & 10.76 & 6.9 & $4.98^{*}$ & $2.71^{*}$ \\
TTI $(\mathrm{mm} \mathrm{Hg} \mathrm{s})$ & 6.5 & 6.7 & 6.9 & 7.2 \\
PVA $(\mathrm{mm} \mathrm{Hg} \mathrm{mL)}$ & 901 & 1486 & 1331 & 1164 \\
\hline
\end{tabular}

$P_{t m}$, Transmural myocardial pressure; $E D P$, End-diastolic pressure; $E_{e s}$, end-systolic elastance; $C_{d}$, diastolic compliance; $T T I$, transmural tension-time index; $P V A$, transmural pressure-volume area. $* P<.05$ for change from baseline.

surrounding wall was thin and not trabeculated; rather, this was considered to be part of the right atrium. RV EF and LV EF were computed according to the Simpson rule as the difference between EDV and end-systolic volume as a percentage of EDV.

\section{Anesthesia and Postoperative Care}

For coronary ligation and ventricular wrap implantation, animals were sedated with combined tiletamine hydrochloride and zolazepam hydrochloride (Telazol, $6 \mathrm{mg} / \mathrm{kg}$ intramuscularly) and endotracheally intubated. Anesthesia was maintained with $1 \%$ to $2 \%$ isoflurane. Animals received magnesium ( $2 \mathrm{gm}$ intravenously), amiodarone (1.5 mg/kg intravenously), and lidocaine ( $3 \mathrm{mg} / \mathrm{kg}$ intravenously) before infarction and received an infusion of amiodarone $(0.01 \mathrm{mg} /[\mathrm{kg} \mathrm{min}])$ and lidocaine $(2 \mathrm{mg} / \mathrm{min})$ for 60 minutes afterward. Animals received buprenorphine $(5 \mu \mathrm{g} / \mathrm{kg}$ intramuscularly every 12 hours for 2 days) for pain control and cefazolin $(4 \mathrm{mg} / \mathrm{kg}$ intramuscularly every 12 hours for 2 days) for antibiotic prophylaxis.

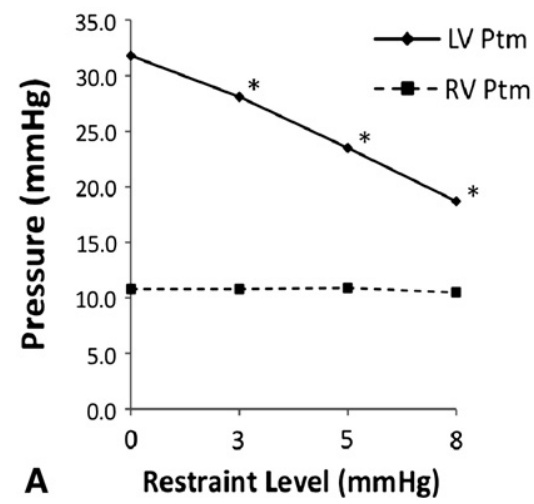

\section{Statistical Analysis}

All data are expressed as mean $+\mathrm{SD}$. A doubly multivariate general linear mixed model with repeated measures design was used in both the acute and long-term studies. ${ }^{27}$ In the acute study, changes in dependent variables were assessed according to restraint level. In the long-term study, changes in dependent variables were assessed with time. Post hoc pairwise comparisons between different restraint levels or different time points were performed with the Bonferroni post hoc test. Statistics were performed with the SPSS statistical software package (version 12.0; SPSS Inc, Chicago, Ill).

\section{RESULTS \\ Acute Studies}

MAP, CVP, $\mathrm{P}_{\mathrm{tm}}$, end-diastolic pressure (EDP), $\mathrm{C}_{\mathrm{d}}, \mathrm{E}_{\mathrm{es}}$, and indices of myocardial energetics for each restraint level for both ventricles are summarized in Table 1. Ventricular restraint did not have any significant effect on $\mathrm{RV} \mathrm{P}_{\mathrm{tm}}$ $(P=.92)$ or indices of $\mathrm{RV} \mathrm{MvO}_{2}(P=.90)$. This is in contrast to the $\mathrm{LV}$, where $\mathrm{P}_{\mathrm{tm}}(P=.03)$ and indices of $\mathrm{MvO}_{2}$ $(P=.002)$ decreased significantly with increasing amounts of restraint (Figure 3, $A)$. RV EDP rose $(P=.02)$ as restraint level was increased. Interestingly, there was a nearly linear relationship between the increase in restraint level and the rise in RV EDP (Figure 3, $B$ ). Restraint had no effect on $\mathrm{RV}$ contractility $\mathrm{E}_{\mathrm{es}}(P=.43)$ but did cause a decrease in $\mathrm{RV} \mathrm{C}_{\mathrm{d}}(P=.01)$ and shifted the end-diastolic pressure-volume relationship to the left. This reduction in $\mathrm{RV} \mathrm{C}_{\mathrm{d}}$ was almost directly proportional to the increase in restraint level. In contrast, restraint had no effect on $\mathrm{LV} \mathrm{C}_{\mathrm{d}}(P=.52)$ or $\mathrm{LV}$ $\mathrm{E}_{\mathrm{es}}(P=.72)$. At restraint levels of $5.0 \mathrm{~mm} \mathrm{Hg}$ and higher, MAP fell $(P=.04)$ and CVP rose $(P=.027)$. MAP decreased by more than $10 \mathrm{~mm} \mathrm{Hg}$ at a restraint level of 8.0 $\mathrm{mm} \mathrm{Hg}$, consistent with tamponade physiology.

\section{Long-Term Studies}

There was no significant change in RV size or function with simulated clinical ventricular restraint (Figure 4). RV

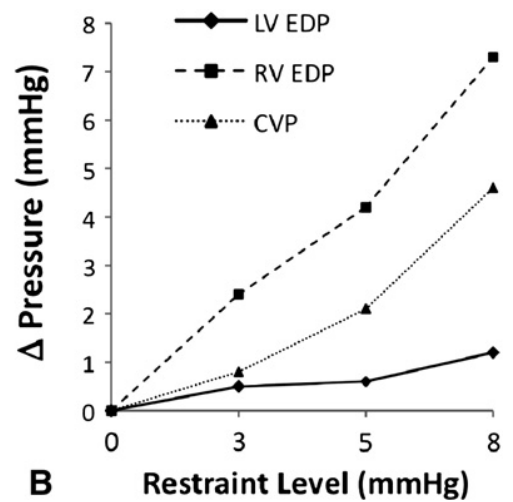

FIGURE 3. Acute effects of restraint on ventricular transmural and filling pressures. A, Ventricular transmural pressure (Ptm) as a function of restraint level. Left ventricular $(L V)$ transmural pressure decreases with increasing restraint, whereas right ventricular $(R V)$ transmural pressure remains unchanged. Asterisk indicates $P<.05$ for change from baseline. B, Changes in end-diastolic pressure $(E D P)$ and central venous pressure $(C V P)$ as a function of restraint level. Left ventricular end-diastolic pressure shows minimal changes with increasing restraint. Right ventricular end-diastolic pressure rises in a nearly linear manner with increases in restraint level. Central venous pressure increases at higher restraint levels, consistent with tamponade. 

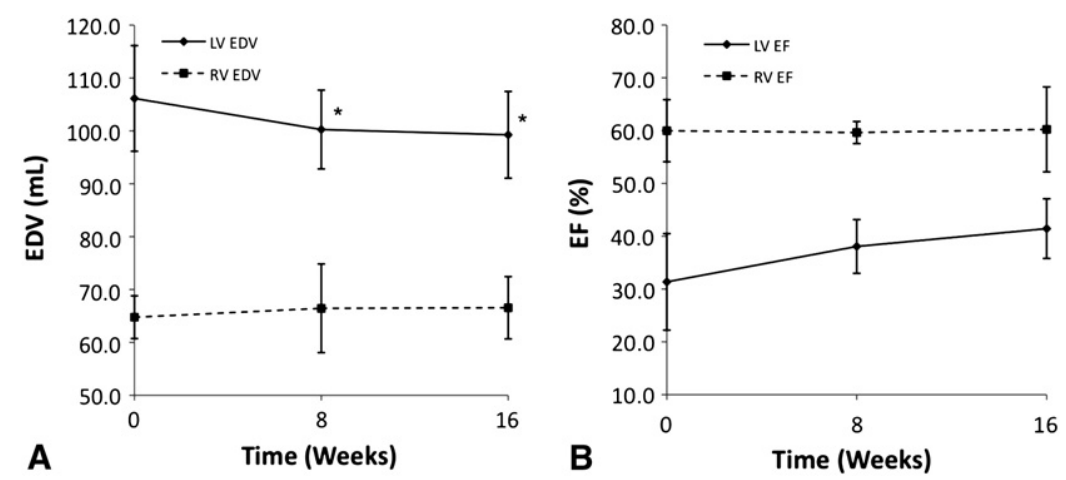

FIGURE 4. Long-term effect of simulated clinical ventricular restraint on end-diastolic volume $(E D V)$ and ejection fraction $(E F)$. A, Left ventricular $(L V)$ end-diastolic volume decreases with time, whereas right ventricular $(R V)$ end-diastolic volume remains unchanged. $\mathrm{B}$, There is a trend toward improvement in left ventricular ejection fraction, although this change is not statistically significant. Right ventricular ejection fraction is unaffected. Time at 0 weeks represents time of restraint wrap implantation. Asterisk indicates $P<.05$ for change from baseline.

EDV values were $64.8 \pm 4.0 \mathrm{~mL}$ at baseline (just before implantation of the restraint wrap) and $66.6 \pm 5.9 \mathrm{~mL}$ after 4 months of treatment $(P=.8)$. RV EF values were $60.0 \%$ $\pm 5.9 \%$ at the start of therapy and $60.2 \% \pm 8.1 \%$ after 4 months $(P=.7)$. In the $\mathrm{LV}$, the simulated clinical restraint wrap resulted in reverse remodeling during the study period (Figure 4). There was a significant reduction in LV EDV, from $106.1 \pm 10.0 \mathrm{~mL}$ at baseline to $99.3 \pm 8.2 \mathrm{~mL}$ after 4 months of therapy $(P=.006)$. There was a trend toward improvement in $\mathrm{LV} \mathrm{EF}$, from $31.4 \% \pm 9.1 \%$ at baseline to $41.4 \% \pm 5.6 \%$ after 4 months; however, this change was not statistically significant $(P=.3)$.

\section{DISCUSSION}

The beneficial effects of ventricular restraint on LV morphology and function have been well documented. ${ }^{10-13} \mathrm{Sev}$ eral studies have demonstrated that restraint therapy can prevent and even reverse pathologic LV remodeling as well as improve global clinical functional status. ${ }^{3-9}$ We previously described a mechanistic explanation for these findings: restraint decreases LV wall stress, as evidenced by decreases in $\mathrm{P}_{\mathrm{tm}}$ and indices of $\mathrm{MvO}_{2} \cdot{ }^{15-16}$ To date, however, there have been no published investigations regarding the effects of restraint on RV mechanics and function.

Restraint therapy by definition can affect the epicardium by either normal stresses (perpendicular forces) or shear stresses (tangential forces). With the AMVR device, the fluid within the balloon is effectively the sole means of achieving restraint. Because a static fluid cannot apply shear stresses, the AMVR balloon affects the epicardium by normal forces only. This is measurable as the pressure within the balloon lumen and allows the quantification of both restraint level and its effects on ventricular mechanics.

To investigate the effect of restraint on each ventricle, we first performed acute hemodynamic studies in which systemic (CVP, MAP) and separate ventricular (EDP, $\mathrm{P}_{\mathrm{tm}}$, $E_{e s}, C_{d}$ ) parameters were measured and calculated as a func- tion of restraint level in 14 normal sheep hearts. In these acute studies, we found that as restraint level was increased to progressively higher levels, $\mathrm{LV} \mathrm{P}_{\mathrm{tm}}$ continued to decrease while effective $L V C_{d}$ and $L V E_{e s}$ remained unaffected, corroborating the results of our previous study. ${ }^{16}$ When restraint level was increased, the LV received the beneficial effect of incremental decreases in LV transmural myocardial pressure while LV diastolic stiffness and systolic contractility remained unchanged.

In contrast to the LV, our data show that any increase in restraint level resulted in a nearly linear rise in RV filling pressure, as measured by RV EDP (Figure 3, B). As a result, $R V P_{t m}$ did not change at all, regardless of the restraint level. Furthermore, as restraint level was increased, overall effective $\mathrm{RV} \mathrm{C}_{\mathrm{d}}$ (the $\mathrm{C}_{\mathrm{d}}$ of the restraint device plus that of the $\mathrm{RV}$ ) decreased. In other words, with the restraint device applied, the RV plus the restraint device apparatus became increasingly stiffer in diastole as the restraint level was increased. At higher restraint levels (where LV $\mathrm{C}_{\mathrm{d}}$ was unchanged), effective RV $C_{d}$ was so diminished as to ultimately impair ventricular filling. At restraint levels of 5 $\mathrm{mm} \mathrm{Hg}$ or greater, overall global tamponade physiology prevailed. Even at these levels, however, the LV continued to receive therapeutic benefit, as evidenced by decrease in $\mathrm{P}_{\mathrm{tm}}$ without any adverse change in effective $\mathrm{LV} \mathrm{C}_{\mathrm{d}}$. We conclude that ventricular restraint affects the RV very differently than the LV.

Why should the mechanics of the RV plus restraint device be different from those of the LV plus restraint device? We postulate that the explanation is related to the thickness of the ventricular wall and the native $C_{d}$ of each ventricle. The relatively thick wall of the LV is less compliant than that of the thin-walled RV. Indeed, the normal RV is substantially more compliant than the LV in diastole (Table 1). We hypothesize that the restraint device acts as another compliance chamber in series with the compliance of the native ventricle. The sum total of 2 compliance chambers in 
series is always less than either of the individual compliance values. Thus the addition of another compliance chamber (the restraint device) in series with each ventricle would cause the restraint device to have a substantially greater effect on overall RV mechanics relative to the LV, because $\mathrm{RV} \mathrm{C}_{\mathrm{d}}$ is greater than that of the LV. The restraint device reduces effective $\mathrm{RV} \mathrm{C}_{\mathrm{d}}$ by a greater degree than its reduction in effective $\mathrm{LV} \mathrm{C} \mathrm{C}_{\mathrm{d}}$. We hypothesize that this is the cause of the effects we measured.

In our acute study, at restraint levels of $5 \mathrm{~mm} \mathrm{Hg}$ and higher there was a significant rise in CVP and reduction in MAP, consistent with overall global tamponade physiology. What caused this tamponade? Was it due to adverse effects of restraint on the LV or the RV? With increasing restraint level, the RV became effectively stiffer with increased filling pressures, whereas no changes in LV stiffness or filling pressures were seen. We conclude that RV mechanics were responsible for the adverse hemodynamic changes causing cardiac tamponade seen at higher restraint levels. Indeed, in the acute studies, we saw no benefit to the RV from restraint therapy at any restraint level.

We sought to correlate findings from the acute studies with those from the longitudinal, long-term study. Our aim was to simulate ventricular restraint therapy as used in clinical trials by applying a mesh wrap in a large-animal model of ischemic dilated cardiomyopathy. The long-term study confirmed that restraint induces reverse remodeling in the LV, as other studies have shown. There was a significant decrease in LV EDV of $6.4 \%$ with our simulated clinical restraint therapy, consistent with results seen in clinical trials of the Acorn CorCap device. ${ }^{3,4}$ The RV, in contrast, did not demonstrate any significant changes in EDV or EF, either before or after heart failure creation, or after the initiation of restraint therapy. Both parameters remained unchanged throughout the entire study duration. As predicted by our acute study results, we conclude that longterm restraint in the setting of LV failure does not have any substantial effect on the RV.

As with clinical devices, we were unable to measure or quantify the amount of restraint applied with our mesh wrap. On the basis of the combined results of the acute and long-term studies, however, we surmise that the restraint level applied in the long-term study was approximately 3.0 $\mathrm{mm} \mathrm{Hg}$ or less. Our assumption is based on the acute study data, in which a restraint level of $3.0 \mathrm{~mm} \mathrm{Hg}$ yielded beneficial changes in LV mechanics without any significant adverse effect on the RV. Although the simplest way to determine the amount of restraint applied would have been to use the AMVR balloon in our long-term study, we did not do so because our goal in the long-term study was to replicate as accurately as possible the clinical use of restraint wraps. Future research may overcome this limitation by using the AMVR balloon to apply restraint in long-term studies. We conclude that restraint therapy, in the scenario of LV failure, can be applied to the entire epicardial surface at low levels to successfully induce LV reverse remodeling without impeding RV function.

One important limitation of this study is that this was not an investigation of RV heart failure. We did not create RV ischemia or dysfunction; RV volume and function remained unchanged before and after diagonal branch coronary artery ligation in our LV heart failure sheep model. In the longterm study, restraint was thus applied to a dysfunctional LV and a normal RV. Our long-term study subjects with normal RVs may not have shown any change in RV size or function simply because their RVs were normal. Our conclusions therefore may not necessarily be applicable in cases of dilated cardiomyopathy involving primary RV failure.

Clinically, LV failure may or may not be accompanied by $\mathrm{RV}$ failure or dilatation. Would restraint therapy be beneficial for a patient with a dilated, dysfunctional RV? Theoretically, restraint should unload the failing RV and promote recovery of ventricular function just as in the left side of the heart. Our acute study results, however, imply that restraint may not provide substantial benefit in RV failure. The acute study was performed in healthy animals. In these subjects with normal LVs, restraint caused decreased LV $\mathrm{P}_{\mathrm{tm}}$, a key parameter identifying beneficial effects on the ventricle. We previously demonstrated in similar shortterm studies that restraint leads to reductions of $\mathrm{LV} \mathrm{P}_{\mathrm{tm}}$ in a dilated, failing $\mathrm{LV}$ as well. ${ }^{16}$ Unlike in the $\mathrm{LV}$, however, short-term studies of the normal RV did not demonstrate any change in $R V P_{t m}$ with restraint. This suggests that restraint may not cause a decrease in $R V \mathrm{P}_{\mathrm{tm}}$ even in a dysfunctional RV. Further investigation of restraint in the setting of $\mathrm{RV}$ failure will be necessary to delineate more fully the role of restraint in $\mathrm{RV}$ dysfunction.

In summary, we demonstrated that ventricular restraint affects the RV and LV differently. Low levels of restraint can be safely applied in LV dilated cardiomyopathy without impeding RV function. The benefit received by the RV in restraint therapy for LV heart failure is, however, unclear. At higher restraint levels, the RV clearly limits overall therapy because of adverse hemodynamic changes related to impaired RV filling. Our data suggest that each ventricle has a different threshold for the amount of restraint that can be applied before impaired filling develops and that individual restraint levels, applied separately to each ventricle, might optimize therapeutic efficacy. With current devices, in which a single restraint level is applied simultaneously to both ventricles, therapeutic efficacy may be limited because the restraint level that promotes optimal reverse LV remodeling may higher than can be tolerated safely by the RV. Ventricle-specific restraint, in which restraint levels are tailored to each ventricle, may be required to optimize therapeutic efficacy. In the scenario of strict LV dysfunction, a partial restraint device, with restraint applied only to the LV epicardium, would allow the application of very high levels 
of restraint for improved LV reverse remodeling without the danger of RV tamponade. Thus future efforts at restraint may involve the simultaneous application of different restraint levels to the $\mathrm{LV}$ and RV, with each level optimized for each ventricle, as opposed to a single concomitant level currently applied to both ventricles.

We thank Drs Vakhtang Tchantchaleishvili and Dahai Wang for assistance with data acquisition and Ethicon, Inc, Somerville, NJ, for providing the polypropylene mesh used in this study.

\section{References}

1. Oh JH, Badhwar V, Mott BD, Li CM, Chiu RC. The effects of prosthetic cardiac binding and adynamic cardiomyoplasty in a model of dilated cardiomyopathy. J Thorac Cardiovasc Surg. 1998;116:148-53.

2. Konertz WF, Shapland JE, Hotz H, Dushe S, Braun JP, Stantke K, et al. Passive containment and reverse remodeling by a novel textile cardiac support device. Circulation. 2001;104(12 Suppl. 1):I270-5.

3. Starling RC, Jessup M, Oh JK, Sabbah HN, Acerk MA, Mann DL, et al. Sustained benefits of the CorCap Cardiac Support Device on left ventricular remodeling: three year follow-up results from the Acorn clinical trial. Ann Thorac Surg. 2007;84:1236-42.

4. Mann DL, Acker MA, Jessup M, Sabbah HN, Starling RC, Kubo SH. Clinical evaluation of the CorCap Cardiac Support Device in patients with dilated cardiomyopathy. Ann Thorac Surg. 2007;84:1226-35.

5. Acker MA. Clinical results with the Acorn cardiac restraint device with and without mitral valve surgery. Semin Thorac Cardiovasc Surg. 2005;17:361-3.

6. Magovern JA. Experimental and clinical studies with the Paracor cardiac restraint device. Semin Thorac Cardiovasc Surg. 2005;17:364-8.

7. Acker MA, Bolling S, Shemin R, Kirklin J, Oh JK, Mann DL, et al. Mitral valve surgery in heart failure: insights from the Acorn Clinical Trial. J Thorac Cardiovasc Surg. 2006;132:568-77, 577.e1-4.

8. Oz MC, Konertz WF, Kleber FX, Mohr FW, Gummert JF, Ostermeyer J, et al. Global surgical experience with the Acorn cardiac support device. J Thorac Cardiovasc Surg. 2003;126:983-91.

9. Power JM, Raman J, Dornom A, Farish SJ, Burrell LM, Tonkin AM, et al. Passive ventricular constraint amends the course of heart failure: a study in an ovine model of dilated cardiomyopathy. Cardiovasc Res. 1999;44:549-55.

10. Pilla JJ, Blom AS, Brockman DJ, Ferrari VA, Yuan Q, Acker MA. Passive ventricular constraint to improve left ventricular function and mechanics in an ovine model of heart failure secondary to acute myocardial infarction. J Thorac Cardiovasc Surg. 2003;126:1467-76.

11. Cheng A, Nguyen TC, Malinowski M, Langer F, Liang D, Daughters GT, et al. Passive ventricular constraint prevents transmural shear strain progression in left ventricle remodeling. Circulation. 2006;114(1 Suppl):I79-86.
12. Saavedra WF, Tunin RS, Paolocci N, Mishima T, Suzuki G, Emala CW, et al. Reverse remodeling and enhanced adrenergic reserve from passive external support in experimental dilated heart failure. J Am Coll Cardiol. 2002;39:2069-76.

13. Sabbah HN. The cardiac support device and the Myosplint: treating heart failure by targeting left ventricular size and shape. Ann Thorac Surg. 2003;75(6 Suppl): S13-9.

14. Pina IL, Swain J. CorCap Food and Drug Administration Panel presentation in $\mathrm{C}_{\mathrm{d}} \mathrm{RH}$ Panel meeting. Washington, DC: The Administration; 2005. Available at: http://www.fda.gov/ohrms/dockets/ac/06/.../2006-4269b1_09_sponsor.pdf.

15. Ghanta RK, Gogbashian A, Laurence R, Cohn LH, Chen FY. A new heart failure device: ventricular restraint decreases myocardial oxygen consumption indices. In: The Society of Thoracic Surgeons, editor. The Society of Thoracic Surgeons 42nd annual meeting. January 30-February 1, 2006, Chicago, Illinois. Chicago: The Society; 2006.

16. Ghanta RK, Rangaraj A, Umakanthan R, Lee L, Laurence RG, Fox JA, et al. Adjustable, physiological ventricular restraint improves left ventricular mechanics and reduces dilatation in an ovine model of chronic heart failure. Circulation. 2007;115:1201-10.

17. Gawne TJ, Gray KS, Goldstein RE. Estimating left ventricular offset volume using dual-frequency conductance catheters. J Appl Physiol. 1987;63:872-6.

18. Baan J, Jong TT, Kerkhof PL, Moene RJ, van Dijk AD, van der Velde ET, et al. Continuous stroke volume and cardiac output from intra-ventricular dimensions obtained with impedance catheter. Cardiovasc Res. 1981;15:328-34.

19. Steendijk P, Van der Velde ET, Baan J. Left ventricular stroke volume by single and dual excitation of conductance catheter in dogs. Am J Physiol. 1993;264(6 Pt 2):H2198-207.

20. Kono A, Maughan WL, Sunagawa K, Hamilton K, Sagawa K, Weisfeldt ML. The use of left ventricular end-ejection pressure and peak pressure in the estimation of the end-systolic pressure-volume relationship. Circulation. 1984;70:1057-65.

21. Suga H. Ventricular energetics. Physiol Rev. 1990;70:247-77.

22. Moainie SL, Gorman JH 3rd, Guy TS, Bowen FW 3rd, Jackson BM, Plappert T, et al. An ovine model of postinfarction dilated cardiomyopathy. Ann Thorac Surg. 2002;74:753-60.

23. Oz M. Surgical implantation of the Acorn cardiac support device. Oper Tech Thorac Cardiovasc Surg. 2002;7(2):107-10.

24. Jauhiainen T, Jarvinen VM, Hekali PE, Poutanen VP, Penttila A, Kupari M. MR gradient echo volumetric analysis of human cardiac casts: focus on the right ventricle. J Comput Assist Tomogr. 1998;22:899-903.

25. Westenberg JJ, Lamb HJ, van der Geest RJ, Bleeker GB, Holman ER, Schalij MJ, et al. Assessment of left ventricular dyssynchrony in patients with conduction delay and idiopathic dilated cardiomyopathy: head-to-head comparison between tissue Doppler imaging and velocity-encoded magnetic resonance imaging. $J$ Am Coll Cardiol. 2006; 47:2042-8.

26. Habbah HN. The cardiac support device and the Myosplint: treating heart failure by targeting left ventricular size and shape. Ann Thorac Surg. 2003;75(6 Suppl): S13-9.

27. Kusuoka H, Hoffman JI. Advice on statistical analysis for. Circulation Research. Circ Res. 2002;91:662-71. 